\title{
Bortezomib retreatment is effective in relapsed multiple myeloma patients - real-life clinical practice data
}

\author{
M. STORK ${ }^{1}$, S. SEVCIKOVA ${ }^{2}$, L. BROZOVA ${ }^{3}$, I. SPICKA ${ }^{4}$, V. MAISNAR ${ }^{5}$, J. MINARIK ${ }^{6}$, A. JUNGOVA ${ }^{7}$, E. GREGORA ${ }^{8}$, R. VELICHOVA ${ }^{3}$, R. HAJEK ${ }^{9}$, \\ T. JELINEK ${ }^{9}$, L. POUR ${ }^{1, *}$
}

${ }^{1}$ Department of Hematology and Oncology, University Hospital Brno, Brno, Czech Republic; ${ }^{2}$ Babak Myeloma Group, Department of Pathological Physiology, Faculty of Medicine, Masaryk University, Brno, Czech Republic; ${ }^{3}$ Institute of Biostatistics and Analyses, Faculty of Medicine, Masaryk University, Brno, Czech Republic; ${ }^{4} 1$ st Medical Department - Clinical Department of Hematology of the First Faculty of Medicine and General Teaching Hospital Charles University, Prague, Czech Republic; ${ }^{5} 4$ th Department of Internal Medicine - Hematology, Faculty Hospital and Charles University in Hradec Kralove, Hradec Kralove, Czech Republic; ${ }^{6}$ Department of Hemato-Oncology, University Hospital Olomouc and Faculty of Medicine and Dentistry, Palacky University Olomouc, Olomouc, Czech Republic; ${ }^{7}$ Hematology and Oncology Department, Charles University Hospital Pilsen, Pilsen, Czech Republic; ${ }^{8}$ Department of Internal Medicine and Hematology, University Hospital Kralovske Vinohrady, Prague, Czech Republic; ${ }^{9}$ Department of Hematooncology, University Hospital Ostrava and Faculty of Medicine University of Ostrava, Ostrava, Czech Republic

*Correspondence: pour.ludek@fnbrno.cz

Received April 30, 2019 / Accepted June 26, 2019

\begin{abstract}
Nowadays, bortezomib, a proteasome inhibitor, is widely used in treatment of newly diagnosed or relapsed multiple myeloma. The aim of this study was to analyze efficiency of bortezomib retreatment in patients with relapsed or refractory multiple myeloma. From 2004 to 2016, 283 patients were retrospectively evaluated at all hematological centers in the Czech Republic. Bortezomib was administered at the standard dosing and in combined therapy with corticosteroids, chemotherapy or thalidomide. Before bortezomib retreatment, $61 \%$ of patients received previous lenalidomide treatment, $40.6 \%$ autologous transplantation, and median number of prior lines of therapy was three. In total, $21 \%$ of patients were refractory to the first bortezomib treatment. In bortezomib retreatment, overall response rate was $34.5 \%$, median progression-free survival was 7.8 months (95\% CI: 6.7-8.9), median duration of response was 10.5 months (95\% CI: 8.0-13.0) and median overall survival was 20.3 months (95\% CI: 17.9-22.7). Grade 3-4 adverse events included thrombocytopenia, neutropenia, anemia and infection. Neuropathy grade 2 or higher occurred in $19.4 \%$ of patients. We conclude that bortezomib retreatment is an effective and safe therapeutic alternative for relapsed or refractory multiple myeloma patients.
\end{abstract}

Key words: multiple myeloma, bortezomib, proteasome inhibitor, repeated treatment, relapse

Multiple myeloma (MM) is the second most common hematological malignancy. It is caused by uncontrolled proliferation of malignant plasma cells in the bone marrow. MM is associated with organ dysfunction, including hypercalcemia, renal insufficiency anemia and bone lesions [1]. In the past 15 years, development of new drugs in the field of MM has been enormous. Immunomodulatory drugs (thalidomide, lenalidomide, pomalidomide), proteasome inhibitors (bortezomib, carfilzomib, ixazomib) or monoclonal antibodies (daratumumab, elotuzumab) in clinical practice fundamentally improved prognosis of newly diagnosed or relapsed MM patients [2].

The first proteasome inhibitor used in MM treatment was bortezomib. Bortezomib reversibly inhibits $26 \mathrm{~S}$ proteasome, a protein complex that degrades abnormal or misfolded proteins. Proteasome inhibition in MM cells leads to apoptosis [3]. Efficiency of bortezomib-based treatment was first shown in relapsed MM patients in the APEX trial. When compared to high dose of dexamethasone, bortezomib treatment achieved a significantly higher efficiency (overall response rate (ORR) $38 \%$ vs. $18 \%$; time to progression (TTP) -6.22 vs. 3.49 months) [4]. In a trial published by Jagannath et al., bortezomib therapy combined with corticosteroids was more effective than bortezomib monotherapy in relapsed MM patients (ORR $75 \%$ vs. $41 \%$; TTP - 13.6 vs. 7.0 months) [5]. In another trial, combined therapy with bortezomib and anthracyclines was more effective than bortezomib monotherapy in bortezomib-naive patients (TTP $9.3 \mathrm{~m}$ vs. $6.5 \mathrm{~m}$ ) [6]. In MMVAR/IFM 2005-04 trial, triplet combination of bortezomib, thalidomide and dexamethasone 
achieved higher efficiency than thalidomide-dexamethasone alone in relapsed MM patients after autologous transplant (TTP was $19.5 \mathrm{~m}$ vs. $13.8 \mathrm{~m}$ ) [7].

In newly diagnosed transplant-ineligible MM patients, bortezomib efficiency was first shown in the VISTA trial. Triple combination bortezomib - melphalan - prednisone achieved significantly better response rate and longer survival intervals when compared to melphalan - prednisone (ORR $71 \%$ vs. $35 \%$, p < 0.001, TTP: $24.4 \mathrm{~m}$ vs. $16.6 \mathrm{~m}$, overall survival (OS): $56.4 \mathrm{~m}$ vs. $43.1 \mathrm{~m}$ ) [8]. In meta-analysis of four randomized multicenter phase III trials, data from 1,572 newly diagnosed transplant eligible MM patients showed significant superiority of bortezomib-based induction treatment over non-bortezomib combinations (progression-free survival (PFS): $35.9 \mathrm{~m}$ vs $28.6 \mathrm{~m}$ ) [9]. These results led to the approval of bortezomib-based regimen as a current standard of treatment for newly diagnosed MM patients $[8,9]$.

Repeated bortezomib treatment has been described in several small retrospective [10-12] and prospective [13] studies or in subgroup analyses of randomized trials for relapsed MM patients [14, 15]. Results from 23 studies of 1051 patients retreated with bortezomib were analyzed in the largest meta-analysis published by Knopf et al. in 2014 . Average ORR was $39.1 \%$ and pooled, weighted average median TTP and OS were 7.5 and 16.6 months, respectively [16]. Another large multi-centric international analysis was recently published by Hulin et al. [17].

This study analyzes bortezomib retreatment in an unselected group of relapsed or refractory MM patients treated in the Czech Republic.

\section{Patients and methods}

Inclusion and exclusion criteria. We retrospectively analyzed all relapsed or refractory MM patients repeatedly treated with bortezomib-containing regimen between April 2004 and December 2016. Patients were from all hematologic centers in the Czech Republic permitted to treat with bortezomib. Patients were enrolled regardless of age, ECOG status, ISS or DS stage. Patients with less than 4 cycles of bortezomib retreatment or with treatment switch to other regiment were not enrolled.

Patients' baseline characteristics and previous treatment. Altogether, 148 women and 135 men were analyzed. Median age at the first bortezomib therapy was 64 years (range 49-78) and 66 years in the bortezomib retreatment (range 49-80), respectively. At the first bortezomib treatment, the median of prior lines of therapy was 1 (range $0-3$ ). Before bortezomib retreatment, the median of prior lines of therapy was 3 (range $1-5) ; 61.5 \%(174 / 283)$ of patients were pretreated with lenalidomide, $45.2 \%$ (128/283) with thalidomide and $40.6 \%(115 / 283)$ of patients underwent high dose chemotherapy followed by autologous peripheral blood stem cell transplant (PBSCT). Before bortezomib retreatment, $20.1 \%(56 / 267)$ of patients were bortezomib refrac- tory. Baseline characteristics of patients are summarized in Table 1.

FISH analysis. Cytogenetic aberrations were analyzed from separated plasma cells by FISH at the time of diagnosis as previously described [18]. Cytogenetic aberrations were evaluable in $43.4 \%(123 / 283)$ of patients. In these patients, rearrangements of the $14 \mathrm{q} 32$ locus $(\mathrm{t}(4 ; 14), \mathrm{t}(14 ; 16), \mathrm{t}(11 ; 14)$, $\mathrm{t}(6 ; 14))$, deletions (del(13)(q14), del(17)(p13)), gain 1q21 and hyperdiploidy were evaluated. Cytogenetic aberrations in our group of patients are summarized in Table 2.

Table 1. Basic characteristics of patients and previous treatment at bortezomib retreatment ( $\mathrm{N}=283$ patients).

\begin{tabular}{ll}
\hline Basic characteristics in bortezomib retreatment & \\
\hline Gender (male/female) & $135 / 148$ \\
Age median (range) & 66 years (49-80) \\
ECOG status & \\
0 & $15.6 \%$ \\
1 & $62.7 \%$ \\
2 & $20.5 \%$ \\
$3+4$ & $1.1 \%$ \\
ISS & \\
I & $35.5 \%$ \\
II & $30.7 \%$ \\
III & $33.8 \%$ \\
Extramedullary mass & $9.6 \%$ \\
Medium prior lines of therapy (range) & $3(1-5)$ \\
Pretreated with lenalidomide & $61.5 \%$ \\
Pretreated with thalidomide & $45.2 \%$ \\
Pretreated with PBSCT & $60.6 \%$ \\
Refractory to bortezomib & $20.1 \%$ \\
\hline
\end{tabular}

Abbreviations: ECOG - Eastern Cooperative Oncology Group; ISS - International Staging System; PBSCT - Peripheral Blood Stem Cell Transplant

Table 2. Cytogenetics in bortezomib retreatment group at the time of diagnosis $(\mathrm{N}=283$ patients $)$.

\begin{tabular}{lll}
\hline Cytogenetics & & Patients \\
\hline Translocation $\mathrm{t}(4 ; 14)$ & evaluated & $75(26.5 \%)$ \\
& positive & $27(9.5 \%)$ \\
Translocation $\mathrm{t}(14 ; 16)$ & evaluated & $26(9.1 \%)$ \\
& positive & $0(0.0 \%)$ \\
Translocation $\mathrm{t}(11 ; 14)$ & evaluated & $32(11.3 \%)$ \\
Translocation $\mathrm{t}(6 ; 14)$ & positive & $10(3.5 \%)$ \\
& evaluated & $10(3.5 \%)$ \\
Deletion $(13)(\mathrm{q} 14)$ & positive & $0(0.0 \%)$ \\
& evaluated & $123(43.4 \%)$ \\
Deletion $(17)(\mathrm{p} 13)$ & positive & $73(25.8 \%)$ \\
& evaluated & $99(34.9 \%)$ \\
Gain $(1 \mathrm{q} 21)$ & positive & $13(4.6 \%)$ \\
& evaluated & $108(38.1 \%)$ \\
Hyperdiploidy & positive & $60(21.2 \%)$ \\
& evaluated & $94(33.2 \%)$ \\
& positive & $37(13.1 \%)$ \\
\hline
\end{tabular}


Data collection. All acquired data were recorded in the RMG (Registry of Monoclonal Gammopathies) of the Czech Myeloma Group. All participants provided written informed consent with inclusion of their data in the RMG. These consent forms were approved by institutional Ethics boards in accordance with the latest Helsinki declaration.

Administered therapy. In bortezomib retreatment, bortezomib was primarily administered at a dose of $1.3 \mathrm{mg} / \mathrm{m}^{2}$ of body surface area. Bortezomib was administered intravenously in $80.9 \%(203 / 251)$ of patients and subcutaneously in $19.1 \%$ (48/251) of patients.

In the first bortezomib treatment, bortezomib was most often administered with cyclophosphamide and dexamethasone (CVD) in $44.9 \%(127 / 283)$ of patients, only with dexamethasone (VD) in 17.3\% (48/283) of patients and with doxorubicin and dexamethasone (BDD) in $13.4 \%(38 / 283)$ of patients. The first bortezomib treatment was followed by PBSCT in $25.8 \%$ (73/283) of patients. Bortezomib in retreatment was most often administered with cyclophosphamide and dexamethasone (CVD) in $21.6 \%(61 / 283)$ of patients, with dexamethasone alone (VD) in 17.7\% (50/283) of patients or with thalidomide and dexamethasone in 14.5\% (41/283) patients. Bortezomib retreatment was followed by PBSCT in $12.0 \%(34 / 283)$ of patients. Therapy was stopped after PBSCT, for unbearable toxicity, after progression or if maximum of 11 cycles was reached (44 doses). Administered therapy is summarized in Table 3.

Response assessment. The primary endpoint of this analysis was treatment response and survival intervals for bortezomib retreatment. Treatment response and time-to-event endpoints (PFS; TTP); duration of response (DOR) and OS were assessed according to the current Inter-

Table 3. Characteristics of administered therapy for bortezomib retreatment ( $\mathrm{N}=\mathbf{2 8 3}$ patients).

\begin{tabular}{lc}
\hline Treatment modality & Patients: n (\%) \\
\hline $\begin{array}{l}\text { CVD therapy } \\
\text { (Cyclophosphamide + Bortezomib + Dexamethasone) }\end{array}$ & $61(21.6 \%)$ \\
$\begin{array}{l}\text { VD therapy } \\
\text { (Bortezomib + Dexamethasone) }\end{array}$ & $50(17.7 \%)$ \\
$\begin{array}{l}\text { VTD therapy } \\
\text { (Bortezomib + Thalidomide + Dexamethasone) }\end{array}$ & $41(14.5 \%)$ \\
$\begin{array}{l}\text { CVTD therapy } \\
\text { (Cyclophosphamide + Bortezomib + Thalidomide + }\end{array}$ & $21(7.4 \%)$ \\
$\begin{array}{l}\text { Dexamethasone) } \\
\text { BDD therapy } \\
\text { (Bortezomib + Doxorubicin + Dexamethasone) }\end{array}$ & $18(6.4 \%)$ \\
$\begin{array}{l}\text { BBD therapy } \\
\text { (Bortezomib + Bendamustine + Dexamethasone) }\end{array}$ & $11(3.9 \%)$ \\
$\begin{array}{l}\text { VMP therapy } \\
\text { (Bortezomib + Melphalan + Prednison) }\end{array}$ & $10(3.5 \%)$ \\
$\begin{array}{l}\text { Bortezomib monotherapy } \\
\text { Other Bortezomib based combinations }\end{array}$ & $7(2.5 \%)$ \\
$\begin{array}{l}\text { Autologous stem cell transplant after bortezomib } \\
\text { retreatment }\end{array}$ & $64(22.7 \%)$ \\
\hline
\end{tabular}

national Myeloma Working Group (IMWG) criteria [19]. Response to treatment was assessed after the treatment withdrawal, at least 60 days after the last bortezomib administration or at least 90 days after high dose chemotherapy, when performed time-to-event endpoints were assessed from the initiation of the first and second line of therapy including bortezomib.

Toxicity assessment. Bortezomib retreatment toxicity was also analyzed. Adverse events (AEs) were graded using the National Cancer Institute Common Terminology Criteria for Adverse Events version 3.0. Safety was evaluated throughout the treatment and during long-term follow-up. Efficiency of the first bortezomib treatment was also analyzed.

Statistical analysis. Data of the patients repeatedly treated with bortezomib were described (only the second administration of bortezomib in a new line of therapy evaluated). Categorical variables were described using absolute and relative frequencies; continuous variables were described by median supplemented with 5 th-95th percentile range. The analysis was performed using the SPSS software (IBM Corp. Released 2016. IBM SPSS Statistics for Windows, Version 24.0. Armonk, NY: IBM Corp.).

\section{Results}

Response to treatment. Treatment response was evaluable in $94.3 \%$ (267/283) of patients. Complete response (CR) and stringent complete response ( $\mathrm{sCR}$ ) were achieved in $6.0 \%(16 / 267)$ of patients, very good partial response (VGPR) in $12.0 \%(32 / 267)$ of patients and partial response (PR) or better response was achieved in 16.5\% (44/267) of patients in the bortezomib retreatment. Overall response rate (ORR

Table 4. Treatment results of the first bortezomib treatment and bortezomib retreatment.

\begin{tabular}{lcc}
\hline \multirow{2}{*}{$\begin{array}{l}\text { Final treatment } \\
\text { response (N=267) }\end{array}$} & $\begin{array}{c}\text { First bortezomib } \\
\text { treatment }\end{array}$ & $\begin{array}{c}\text { Bortezomib } \\
\text { retreatment }\end{array}$ \\
\cline { 2 - 3 } & \multicolumn{2}{c}{ Patients: n (\%) } \\
\hline ORR & $194(72.7 \%)$ & $92(34.5 \%)$ \\
SCR & $7(2.6 \%)$ & $4(1.5 \%)$ \\
CR & $33(12.4 \%)$ & $12(4.5 \%)$ \\
VGPR & $90(33.7 \%)$ & $32(12.0 \%)$ \\
PR & $64(24.0 \%)$ & $44(16.5 \%)$ \\
MR & $17(6.4 \%)$ & $11(4.1 \%)$ \\
SD & $17(6.4 \%)$ & $20(7.5 \%)$ \\
PD & $39(14.6 \%)$ & $144(53.9 \%)$ \\
Survival intervals & & \\
Median PFS (95\% CI) & 16.1 months (14.3-17.8) & 7.8 months $(6.7-8.9)$ \\
Median DOR (95\% CI) & 17.5 months $(15.3-19.7)$ & 10.5 months $(8.0-13.0)$ \\
Median TTP (95\% CI) & 16.1 months (14.3-17.8) & 8.0 months $(6.9-9.2)$ \\
\hline
\end{tabular}

LogRank test for survival intervals; Abbreviation: ORR - overall response rate, sCR - stringent complete response, CR - complete response, VGPR Very good partial response, $\mathrm{PR}$ - partial response, $\mathrm{MR}$ - minor response, $\mathrm{SD}$ - stable disease, $\mathrm{PD}$ - progressive disease, $\mathrm{PFS}$ - progression free survival, DOR - duration of response, TTP - time to progression 
A

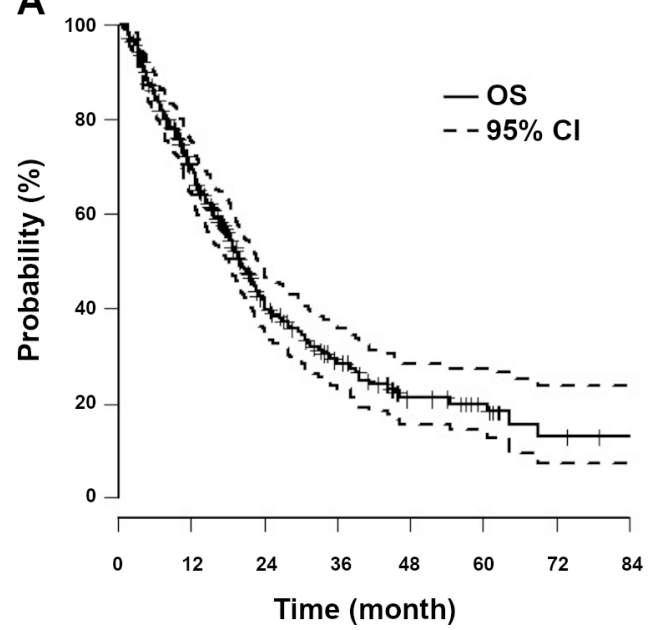

C

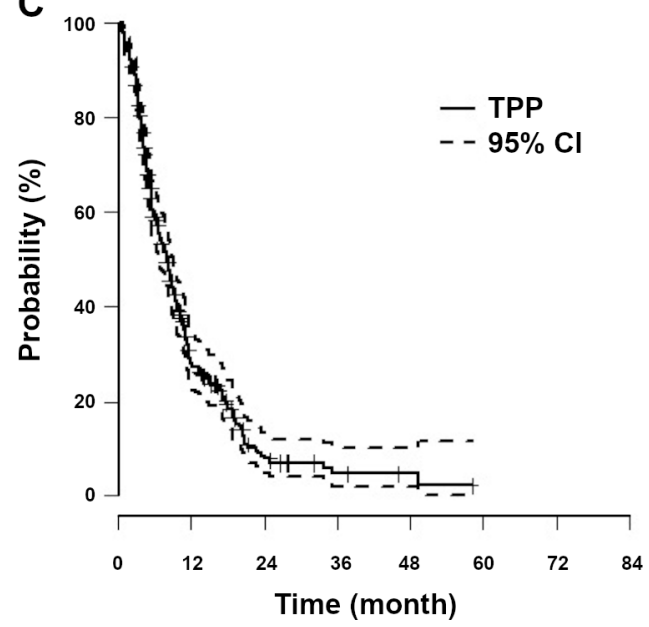

B
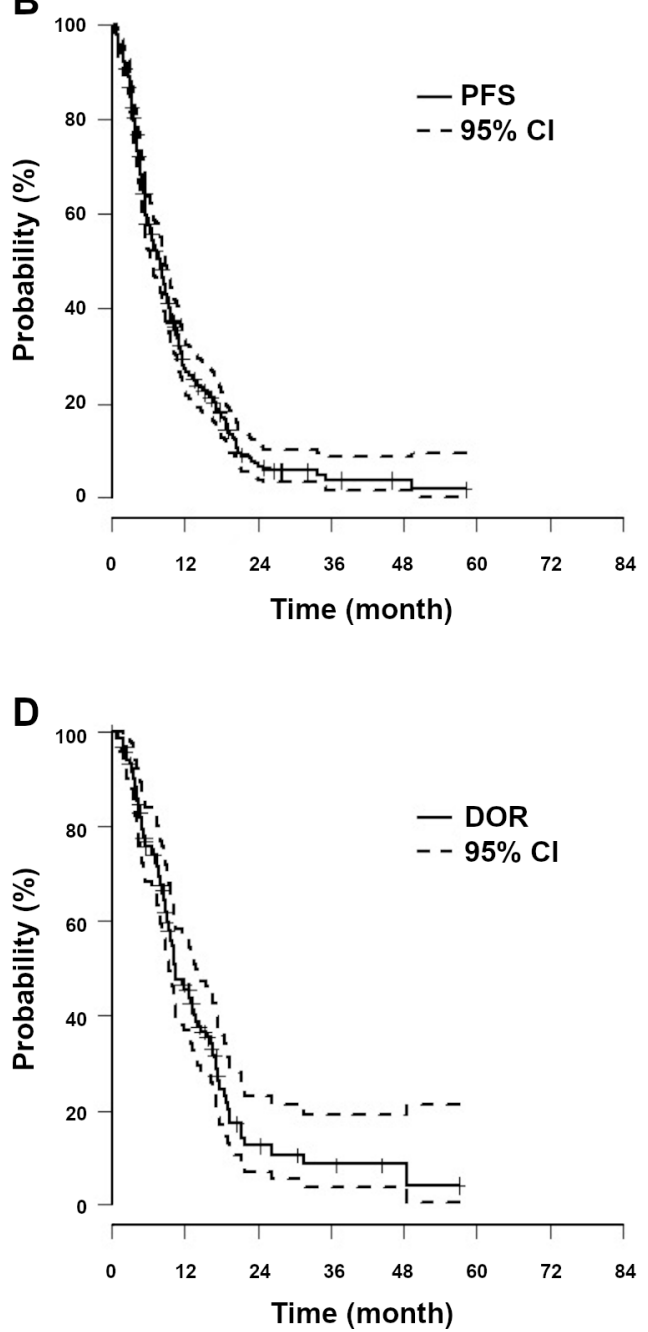

Figure 1. Kaplan-Meier curves for survival intervals in bortezomib retreatment. A) shows the overall survival in bortezomib retreatment group; the median overall survival was 20.3 months (95\% CI: 17.9-22.7). B) shows the progression free survival in bortezomib retreatment group; the median of progression free survival was 7.8 months (95\% CI: 6.7-8.9). C) shows the time to progression in bortezomib retreatment group; the median of time to progression was 8.0 months (95\% CI: 6.9-9.2). D) shows the duration of response in bortezomib retreatment group; the median of duration of response was 10.5 months (95\% CI: 8.0-13.0).

- PR and better) was achieved in 34.5\% (92/267) of patients. Minor response (MR) was achieved in $4.1 \%(11 / 267)$ of patients and $7.5 \%(20 / 267)$ of patients had stable disease (SD). In total, 53.9\% (144/267) of patients progressed during bortezomib retreatment or within 60 days after bortezomib retreatment withdrawal.

Survival intervals. The median PFS was 7.8 months $(95 \%$ CI: 6.7-8.9), median DOR 10.5 months (95\% CI: 8.0-13.0), median TTP was 8.0 months (95\% CI: 6.9-9.2), and median OS was 20.3 months (95\% CI: 17.9-22.7) in the bortezomib retreatment group. Kaplan-Meier curves for survival intervals are shown in Figure 1. All results, including survival intervals and treatment response, were significantly better in the first bortezomib treatment than in the bortezomib retreatment. Comparison between the first bortezomib treatment and bortezomib retreatment is shown in Table 4 .

Adverse events. As expected, treatment toxicity was mainly hematologic and feasible. In the bortezomib retreatment group, the most common serious side effects (grade $3-4)$ were thrombocytopenia $(26.1 \% ; 73 / 283)$, neutropenia $(19.1 \% ; 53 / 283)$, anemia $(16.5 \% ; 46 / 283)$ and infectious complications $(14.8 \%$; 41/283). Neuropathy was present in $34.2 \%(95 / 283)$ of patients in the bortezomib retreatment.

Neuropathy grade 2 was present in $16.2 \%(45 / 283)$ and grade 3 in $3.2 \%(9 / 283)$ of patients. During the second bortezomib treatment, one patient died due to infection (grade 5). Toxicity of the first bortezomib treatment and bortezomib retreatment is listed in Table 5 . 


\section{Discussion}

Efficacy of new drugs used for MM treatment improved survival as well as quality of life of MM patients. Unfortunately, many new drugs are not widely available in real-life clinical practice [20-23]. Bortezomib still remains an effective and widely available treatment option for newly diagnosed or relapsed MM [4-9, 22-24]. Nowadays, most relapsed MM patients are already pretreated with bortezomib $[8,9]$. In case of limited available treatment options in clinical practice, retreatment with bortezomib in relapsed $\mathrm{MM}$ patients is an acceptable and frequent option, especially in the era of generic bortezomib [22-23].

The largest meta-analysis of bortezomib retreatment was published by Knopf et al. in 2014 [16]. In a subgroup analysis, patients with four or less previous treatment lines had better ORR and TTP results, when compared with more pretreated patients (ORR: $43.4 \%$ vs. 29.2\%; TTP: $8.2 \mathrm{~m}$ vs. $7.1 \mathrm{~m}$ ) [16]. In our analysis, median of previous treatment was three, and our results are more comparable to the less pretreated subgroup from the Knopf meta-analysis (ORR: 34.5\%; TTP: $8.0 \mathrm{~m}$ ).

In the Knopf meta-analysis, subgroup of only relapsed (not refractory) patients to first bortezomib treatment had much better ORR and TPP results than refractory patients subgroup (ORR 57.2\% vs. 18.9\%; median TTP $8.5 \mathrm{~m}$ and $5.9 \mathrm{~m}$ ) [16]. In our analysis, $72.7 \%$ of patients responded to the first bortezomib treatment, and only $20 \%$ of patients were refractory. It is obvious that our results are similar to the non-refractory subgroup from the Knopf meta-analysis.

In a trial published by Petrucci et al., 130 bortezomib pretreated relapsed $\mathrm{MM}$ patients were retreated with bortezomib or bortezomib combined with dexamethasone. Patients who were bortezomib refractory were primarily excluded from this trial, and median of previous treatment lines was two; ORR was $40 \%$ and median TTP 7.5 months [13]. These results are comparable to our analysis. It is obvious that patients in the Petrucci trial were less pretreated than our group; on the other hand, only bortezomib monotherapy or combination with corticosteroids was used. More than half of our patients had triplet combination in bortezomib retreatment; in $12 \%$ of these patients, treatment was followed by autologous PBSCT.

In another analysis, published by Hulin et al. better retreatment results were achieved when compared to our analysis. In patients with 4 previous lines of therapy ORR was $46 \%$ and median PFS was 11.4 months. Results can be explained with relatively high number $(20 \%)$ of patients treated with bortezomib plus lenalidomide. Unfortunately, in this analysis there is no evidence about number of bortezomib refractory patients before retreatment. [17].

When compared to other treatment options for bortezomib relapsed or refractory patients, bortezomib retreatment efficiency is acceptable.

Lenalidomide is nowadays the gold standard of treatment for relapsed MM patients. In bortezomib pretreated relapsed MM patients, lenalidomide-based treatment achieved ORR in $60.6 \%$ of patients, and median TTP was 13.4 months [25]. Lenalidomide-based relapse treatment inside of clinical trials seems to be more effective than bortezomib retreatment in our analysis. On the other hand, $61.5 \%$ of our patients were already pretreated by lenalidomide before bortezomib retreatment, and direct comparison of bortezomib retreatment to lenalidomide treatment is missing.

Carfilzomib, the second-generation proteasome inhibitor, was directly compared to the bortezomib retreatment in a sub-analysis of the ENDEAVOR trial. Median PFS was much longer in the carfilzomib arm when compared to the bortezomib retreatment arm (15.6 m vs. 8.1m). However, bortezomib refractory patients were excluded from the ENDEAVOR trial [14].

In our group of patients, serious toxicity (grade 3-4) of bortezomib retreatment was comparable to bortezomib retreatment in the Knopf meta-analysis. Incidence of neuropathy was higher in our analysis than in the meta-analysis [16]. This finding can be explained by higher number of patients treated with combined treatment with thalidomide

Table 5. Adverse events in the first bortezomib treatment and bortezomib retreatment $(\mathrm{N}=283$ patients).

\begin{tabular}{|c|c|c|c|c|c|c|}
\hline \multirow[b]{2}{*}{ Adverse events* } & \multicolumn{3}{|c|}{$\begin{array}{l}\text { First bortezomib treatment } \\
\qquad(\mathrm{N}=283)\end{array}$} & \multicolumn{3}{|c|}{$\begin{array}{l}\text { Bortezomib retreatment } \\
\qquad(\mathrm{N}=283)\end{array}$} \\
\hline & Total & Grade 3 & Grade 4 & Total & Grade 3 & Grade 4 \\
\hline Anemia & $222(78.4 \%)$ & $30(10.7 \%)$ & $1(0.4 \%)$ & $232(81.9 \%)$ & $40(14.3 \%)$ & $6(2.2 \%)$ \\
\hline Thrombocytopenia & $175(61.8 \%)$ & $24(8.6 \%)$ & $13(4.6 \%)$ & $206(72.8 \%)$ & $47(16.8 \%)$ & $26(9.3 \%)$ \\
\hline Neutropenia & $171(60.4 \%)$ & $34(12.1 \%)$ & $13(4.6 \%)$ & $169(59.7 \%)$ & $40(14.3 \%)$ & $13(4.7 \%)$ \\
\hline Infection & $150(53.0 \%)$ & $32(11.4 \%)$ & $1(0.4 \%)$ & $167(59.0 \%)$ & $39(14.1 \%)$ & $2(0.7 \%)$ \\
\hline \multirow[t]{2}{*}{ Fatigue } & $149(52.6 \%)$ & $8(2.8 \%)$ & $0(0.0 \%)$ & $166(58.6 \%)$ & $9(3.2 \%)$ & $3(1.1 \%)$ \\
\hline & Total & Grade 2 & Grade 3 & Total & Grade 2 & Grade 3 \\
\hline Neuropathy & $167(59.0 \%)$ & $51(18.1 \%)$ & $24(8.5 \%)$ & $149(52.6 \%)$ & $45(16.2 \%)$ & $9(3.2 \%)$ \\
\hline Diarrhea & $79(27.9 \%)$ & $21(7.5 \%)$ & $6(2.1 \%)$ & $50(17.6 \%)$ & $15(5.4 \%)$ & $7(2.5 \%)$ \\
\hline Nausea & $93(32.8 \%)$ & $28(10.0 \%)$ & $3(1.1 \%)$ & $71(25.0 \%)$ & $20(7.2 \%)$ & $5(1.8 \%)$ \\
\hline
\end{tabular}

${ }^{*}$ count (relative frequencies) 
in our analysis, but incidence of serious neuropathy (grade 3) was comparable in both analyses. Polyneuropathy incidence was not increased by bortezomib retreatment in our analysis. On the other hand, our results can be explained by excluding patients with severe neuropathy from our group after the first bortezomib treatment.

Rationale for bortezomib retreatment efficiency can be explained by the clonal theory of MM [26]. We assume that the bortezomib retreatment can affect sub-clones of plasma cells selected by previous non-bortezomib therapy. In a subgroup of patients, who had bortezomib primotherapy followed by long remission and then relapse treated by bortezomib retreatment (without non-bortezomib treatment), efficiency of bortezomib retreatment can be explained by clonal drift during long remission, re-sensitizing patient to bortezomib treatment again [26].

Our real-life clinical practice data from the Czech Republic reflect our experience with repeated bortezomib treatment. Our data are the second largest-ever published group of patients retreated with bortezomib in real-life clinical practice conditions, outside of clinical trials. We found bortezomib retreatment as still an effective treatment option in relapsed MM patients.

When compared to other published analyses, it is obvious that refractory status to the first bortezomib treatment has high impact on bortezomib retreatment results. We found that bortezomib retreatment effect in more pretreated patients may be improved by more aggressive treatment protocols, such as triplet combination with alkylators or thalidomide.

Moreover, bortezomib retreatment is a well-tolerated treatment option, especially in patients who did not suffer serious toxicity of the first bortezomib treatment. In our pretreated group of patients with median of three prior lines of therapy, one third of patients had treatment response and one-half had at least stable disease. In the group of responders, response lasted more than ten months. From the practical point of view, we found these results to be a success, especially when there were no other treatment options. Our analysis is also important from the pharmacoeconomic point of view, especially in the era of generic bortezomib, since the price of new drugs is extremely high. According to our analysis from real-life clinical practice, bortezomib retreatment can be effectively used even in pretreated relapsed MM patients.

Acknowledgments: The authors would like to thank all patients, their caregivers and RMG data coordinators for participating in this study.

\section{References}

[1] KYLE RA, RAJKUMAR SV. Multiple myeloma. Blood 2008; 111: 2962-2972. https://doi.org/10.1182/ blood-2007-10-078022
[2] RAJKUMAR SV, KUMAR S. Multiple Myeloma: Diagnosis and Treatment. Mayo Clin Proc 2016; 91: 101-119. https:// doi.org/10.1016/j.mayocp.2015.11.007

[3] MOHAN M, MATIN A, DAVIES FE. Update on the optimal use of bortezomib in the treatment of multiple myeloma. Cancer Manag Res 2017; 9: 51-63. https://doi.org/10.2147/ CMAR.S105163

[4] RICHARDSON PG, SONNEVELD P, SCHUSTER MW, IRWIN D, STADTMAUER EA et al. Bortezomib or high-dose dexamethasone for relapsed multiple myeloma. N Engl J Med 2005; 352: 2487-2498. https://doi.org/10.1056/NEJMoa043445

[5] JAGANNATH S, BARLOGIE B, BERENSON J, SIEGEL D, IRWIN D et al. A phase 2 study of two doses of bortezomib in relapsed or refractory myeloma. Br J Haematol 2004; 127: 165-172. https://doi.org/10.1111/j.1365-2141.2004.05188.x

[6] ORLOWSKI RZ, NAGLER A, SONNEVELD P, BLADE J, HAJEK $\mathrm{R}$ et al. Randomized phase III study of pegylated liposomal doxorubicin plus bortezomib compared with bortezomib alone in relapsed or refractory multiple myeloma: combination therapy improves time to progression. J Clin Oncol 2007; 25: 3892-3901. https://doi.org/10.1200/ JCO.2006.10.5460

[7] GARDERET L, IACOBELLI S, MOREAU P, DIB M, LAFON I et al. Superiority of the triple combination of bortezomibthalidomide-dexamethasone over the dual combination of thalidomide-dexamethasone in patients with multiple myeloma progressing or relapsing after autologous transplantation: the MMVAR/IFM 2005-04 Randomized Phase III Trial from the Chronic Leukemia Working Party of the European Group for Blood and Marrow Transplantation. J Clin Oncol 2012; 30: 2475-2482. https://doi.org/10.1200/ JCO.2011.37.4918

[8] SAN MIGUEL JF, SCHLAG R, KHUAGEVA NK, DIMOPULOS MA, SHPILBERG O et al. Bortezomib plus Melphalan and Prednisone for Initial Treatment of Multiple Myeloma. N Engl J Med 2008; 359: 906-917. https://doi.org/10.1056/ NEJMoa0801479

[9] SONNEVELD P, GOLDSCHMIDT H, ROSINOL L, BLADE J, LAHUERTA JJ et al. Bortezomib-based versus Nobortezomib - based induction treatment before autologous stem-cell transplantation in patients with previously untreated multiple myeloma: a meta-analysis of phase III randomized, controlled trials. J Clin Oncol 2013; 31: 3279-3287. https://doi. org/10.1200/JCO.2012.48.4626

[10] HRUSOVSKY I, EMMERICH B, VON ROHR A, VOEGELI J, TAVERNA $C$ et al. Bortezomib retreatment in relapsed multiple myeloma - results from a retrospective multicentre survey in Germany and Switzerland. Oncology 2010; 79: 247-254. https://doi.org/10.1159/000322866

[11] TAVERNA C, VOEGELI J, TROJAN A, OLIE RA, VON ROHR A. Effective response with bortezomib retreatment in relapsed multiple myeloma--a multicentre retrospective survey in Switzerland. Swiss Med Wkly 2012; 142: 13562. https://doi.org/10.4414/smw.2012.13562 
[12] WOLF J, RICHARDSON PG, SCHUSTER M, LEBLANC A, WALTERS IB et al. Utility of bortezomib retreatment in relapsed or refractory multiple myeloma patients: a multicenter case series. Clin Adv Hematol Oncol 2008; 6: 755-760.

[13] PETRUCCI MT, GIRALDO P, CORRADINI P, TEIXEIRA A, DIMOPOULOS MA et al. A prospective, international phase 2 study of bortezomib retreatment in patients with relapsed multiple myeloma. Br J Haematol 2013; 160: 649-659. https://doi.org/10.1111/bjh.12198

[14] DIMOPOULOS MA, MOREAU P, PALUMBO A, JOSHUA D, POUR L et al. Carfilzomib and dexamethasone versus bortezomib and dexamethasone for patients with relapsed or refractory multiple myeloma (ENDEAVOR): a randomised, phase 3, open-label, multicentre study. Lancet Oncol 2016; 17: 27-38. https://doi.org/10.1016/S1470-2045(15)00464-7

[15] PALUMBO A, CHANAN-KHAN A, WEISEL K, NOOKA AK, MASSZI T et al. Daratumumab, Bortezomib, and Dexamethasone for Multiple Myeloma. N Engl J Med 2016; 375:754-766. https://doi.org/10.1056/NEJMoa1606038

[16] KNOPF KB, DUH MS, LAFEUILLE MH, GRAVEL J, LEFEBVRE $P$ et al. Meta-analysis of the efficacy and safety of bortezomib re-treatment in patients with multiple myeloma. Clin Lymphoma Myeloma Leuk 2014; 14: 380-388. https://doi. org/10.1016/j.clml.2014.03.005

[17] HULIN C, DE LA RUBIA J, DIMOPOULOS MA, TERPOS E, KATODRITOU E et al. Bortezomib retreatment for relapsed and refractory multiple myeloma in real-world clinical practice. Health Sci Rep 2018; 2: e104. https://doi. org/10.1002/hsr2.104

[18] ROSS FM, AVET-LOISEAU H, AMEYE G, GUTIERREZ NC, LIEBISCH P et al. European Myeloma Network. Report from the European Myeloma Network on interphase FISH in multiple myeloma and related disorders. Haematologica 2012; 97: 1272-1277. https://doi.org/10.3324/haematol.2011.056176
[19] RAJKUMAR SV, DIMOPOULOS MA, PALUMBO A BLADE J, MERLINI G et al. International Myeloma Working Group updated criteria for the diagnosis of multiple myeloma. Lancet Oncol 2014; 15: e538-548. https://doi. org/10.1016/S1470-2045(14)70442-5

[20] NOOKA AK, KASTRITIS E, DIMOPOULOS MA, LONIAL S. Treatment options for relapsed and refractory multiple myeloma. Blood 2015; 125: 3085-3099. https://doi.org/10.1182/ blood-2014-11-568923

[21] ROY A, KISH JK, BLOUDEK L, SIEGEL DS, JAGANNATH $S$ et al. Estimating the Costs of Therapy in Patients with Relapsed and/or Refractory Multiple Myeloma: A Model Framework. Am Health Drug Benefits 2015; 8: 204-215.

[22] CORIU D, DYTFELD D, NIEPEL D, SPICKA I, MARKULJAK I et al. Real-world multiple myeloma management practice patterns and outcomes in selected Central and Eastern European countries. Pol Arch Intern Med 2018; 128: 500511. https://doi.org/10.20452/pamw.4305

[23] RAAB MS, CAVO M, DELFORGE M, DRIESSEN M, FINK L et al. Multiple myeloma: practice patterns across Europe. Br J Haematol 2016; 175: 66-76. https://doi.org/10.1111/ bjh.14193

[24] BHANDARI M, JAGANNATH S. Repeated complete responses with bortezomib in a heavily pretreated primary refractory patient with light chain multiple myeloma. Clin Lymphoma Myeloma 2007; 7: 373-375. https://doi. org/10.3816/CLM.2007.n.016

[25] DIMOPOULOS MA, CHEN C, SPENCER A, NIESVIZKY $\mathrm{R}$, ATTAL $\mathrm{M}$ et al. Long-term follow-up on overall survival from the MM-009 and MM-010 phase III trials of lenalidomide plus dexamethasone in patients with relapsed or refractory multiple myeloma. Leukemia 2009; 23: 2147-2152. https://doi.org/10.1038/leu.2009.147

[26] KEATS JJ, CHESI M, EGAN JB, GARBITT VM, PALMER $\mathrm{SE}$ et al. Clonal competition with alternating dominance in multiple myeloma. Blood 2012; 120: 1067-1076. https://doi. org/10.1182/blood-2012-01-405985 